Seraina Plotke

\title{
Bildgestalt aus den Lettern - Die Intermedialität der visuellen Poesie im 17. Jahrhundert
}

Visuelle Poesie als besondere Spielart der Lyrik ist heute in erster Linie in ihren Ausprägungen des 20. Jahrhunderts bekannt. Avantgardistische Künstlerbewegungen wie der Dadaismus oder der Futurismus, literarische Strömungen wie die Konkrete Poesie, Autoren wie Guillaume Apollinaire und Ernst Jandl, sie alle haben Textgebilde hervorgebracht, die die graphische Anordnung von Wörtern und Buchstaben auf der Blattfläche nutzen, um dadurch Sinn zu erzeugen. ${ }^{1}$ Präsentiert werden Schrift-Bilder, in denen von der konventionellen Gebrauchsweise des Alphabets abgewichen wird, das gemeinhin (nur) darauf ausgerichtet ist, dass die einzelnen Zeichen digital entschlüsselt werden und die besondere Stellung der Wörter auf dem Blatt oder auch die genaue Ausformung des einzelnen Buchstabens keine signifikante Rolle spielen. ${ }^{2}$ Für sogenannt visuelle Texte jedweder Art und Epoche gilt hingegen, dass die Schriftzeichen sowohl digital als auch analog zu rezipieren sind und erst aus dem Zusammenspiel der beiden Wahrnehmungsvarianten die vollständige Bedeutung des Textgebildes zu erschließen ist. ${ }^{3}$ Oder anders gesagt: Visuelle Texte verwenden sowohl bildnerisch-graphische als

1 Siehe mit einführendem Charakter: Jeremy Adler, Ulrich Ernst: Text als Figur. Visuelle Poesie von der Antike bis zur Moderne. Katalog der Ausstellung in der Herzog August Bibliothek Wolfenbüttel. Weinheim 1987, S. 212-318; Klaus Peter Dencker: Optische Poesie. Von den prähistorischen Schriftzeichen bis zu den digitalen Experimenten der Gegenwart. Berlin 2011, S. 312-430; Jörg Robert: Einführung in die Intermedialität. Darmstadt 2014, S. 59-77.

2 Die Buchstaben des lateinischen Alphabets zeichnen sich gemäß Nelson Goodman dadurch aus, dass sie »differenziert « und »disjunkt« sind - Goodman benutzt dafür auch den Ausdruck »digital (vgl. Nelson Goodman: Languages of Art. An Approach to a Theory of Symbols. Indianapolis 1968, dt.: Sprachen der Kunst. Entwurf einer Symboltheorie. Übers. von Bernd Philippi. Frankfurt a. M. 1995, S. 154-157). Das heißt, dass die alphabetische Schrift im Zuge der Decodierung grundsätzlich Ja-Nein-Entscheidungen nötig macht: Das a im Wort `Band ist entweder ein a oder kein a (im letzteren Fall handelt es sich u. U. um das Wort `Bund `); ob das betreffende Wort in Antiqua oder kursiv gesetzt, gemalt oder gedruckt, gar vertikal (etwa in einer Leuchtreklame) ausgerichtet ist, spielt für diese Frage keine Rolle (vgl. Sabine Gross: Schrift-Bild. Die Zeit des Augen-Blicks. In: Georg Christoph Tholen, Michael O. Scholl (Hgg.): Zeit-Zeichen. Aufschübe und Interferenzen zwischen Endzeit und Echtzeit. Weinheim 1990 (VCH Acta humaniora), S. 231-246, hier S. 242). 3 Zur Differenzierung digitaler und analoger Zeichen mit Blick auf die Spezifik der visuellen Poesie siehe Seraina Plotke: Gereimte Bilder. Visuelle Poesie im 17. Jahrhundert, München 2009, S. 41-43. 
auch verbal-diskursive Mittel, um Sinn zu stiften, und zwar - im Unterschied zu anderen intermedialen Gattungen - indem sie diese in eins setzen, gleichsam verschränken.

Visuelle Poesie ist demnach grundsätzlich ein Hybrid- oder auch Kipp-Phänomen. Sie zeichnet sich genretypisch dadurch aus, dass ein und dasselbe Zeichenmaterial, in der Regel die Tinte oder die Druckerschwärze auf dem Blatt, in unterschiedlichen Signifikationsmodi registriert und dechiffriert, also einerseits als diskursiver Text gelesen, andererseits als Bild oder Graphik betrachtet werden kann. ${ }^{4}$ Diese Hybridisierung der Zeichen hat wesentliche Konsequenzen für den Rezeptionsprozess und trägt dazu bei, dass visuelle Texte Bedeutungsschichten in sich zu tragen vermögen, die überhaupt erst aus der Synthetisierung der je spezifischen Wahrnehmungsweisen erwachsen und die sich von denen anderer intermedialer Formen strukturell unterscheiden. Da insbesondere der Leseweg nicht von vornherein vorgegeben ist wie bei konventionellen Texten, nutzen viele visuelle Gedichte auch diese Dimension, indem sie die Leserichtung oder den Ablauf des Aneignungsprozesses des Gebildes zum Instrument der Sinngebung machen und in dessen Bedeutungshorizont mit einbauen.

Tatsächlich handelt es sich bei der visuellen Poesie nicht um eine Erfindung des 20. Jahrhunderts, sondern um ein literarisches Genre, das allein in Europa eine lange Tradition besitzt, die sich bis in die Zeit des Hellenismus zurückverfolgen lässt. ${ }^{5}$ Dass das humanistische Interesse mit der Wiederentdeckung der griechischen Antike in der Renaissance auch auf die hellenistischen Technopaegnien fiel, wie die ältesten Beispiele visueller Poesie in der Forschungsgeschichte oft bezeichnet wurden, ${ }^{6}$ ist wenig verwunderlich. In den Bukolikerhandschriften und in der Anthologia Graeca sind insgesamt sechs griechische Epigramme überliefert, die aufgrund unterschiedlicher Verslängen bestimmte Umrisse abbilden: ein Flügelpaar, ein Ei, ein Beil, eine Hirtenflöte und zwei Altäre. In den einzelnen Überlieferungsträgern wurden diese Figurengedichte häufig alle dem hellenistischen Dichter Theokrit zugeschrieben, der deshalb noch bis ins späte

\footnotetext{
4 Vgl. Gross (Anm. 2).
}

5 Siehe jüngst Ulrich Ernst (Hg.): Visuelle Poesie. Historische Dokumentation theoretischer Zeugnisse. Bd. 1: Von der Antike bis zum Barock. Berlin 2012; Dencker (Anm. 1). Grundlegend: Adler, Ernst (Anm. 1). Des Weiteren auch: Julika Funk, Karola Mono (Hgg.): Den Buchstaben ein optisches Gefäß geben: Text als Figur. Visuelle Poesie von der Antike bis zur Moderne. Katalog zu einer Ausstellung der Bibliothek der Universität Konstanz vom 5. Juli bis 15. August 1988. Konstanz 1988; Dick Higgins: Pattern poetry. Guide to an unknown literature. Albany 1987; Robert Massin: Buchstabenbilder und Bildalphabete. Ravensburg 1970.

6 Der Begriff stammt vom spätantiken Dichter Ausonius (opusc. 16,1 Prete), der damit allerdings nicht Figurengedichte bezeichnet, sondern unspezifisch spielerische Phänomene der Dichtkunst. 
17. Jahrhundert als doppelter Gründervater der Bukolik und der visuellen Poesie galt (vgl. Abb. 1). ${ }^{7}$

Richtungsweisend für die frühneuzeitliche produktive Auseinandersetzung mit dem durch die griechischen Archegeten autorisierten Gedichttypus war dessen Aufnahme in die Poetices libri septem von Julius Caesar Scaliger, die 1561 postum erschienen und als Beispiele zur Nachahmung zwei Ei-Gedichte präsentieren. ${ }^{8}$ Während der italienische Humanist damit (noch) auf eine der aus der Antike überlieferten Konturen rekurriert, wurde das kreative Potenzial, das in der Gattung steckt, im 17. Jahrhundert produktiv entfaltet, indem Gedichte entstanden, die denkbar vielseitige Formen und Figuren wiedergeben. Als besonders beliebte Sujets kristallisierten sich die Pokal-, die Kreuz- und die Pyramidengestalt heraus, ${ }^{9}$ daneben finden sich aber auch Gedichte, die Herzen, Bäume, Äpfel, Kerzen, Bahren oder Sanduhren und vieles mehr abbilden (vgl. Abb. 2, 3 u. 4). ${ }^{10}$

7 Vgl. ausführlich Silvia Strodel: Zur Überlieferung und zum Verständnis der hellenistischen Technopaignien. Frankfurt a.M. 2002 (Studien zur klassischen Philologie; 132). Drei der sechs überlieferten hellenistischen Figurengedichte - die Gedichte in Ei-, in Beil- und in Flügelform - stammen vom alexandrinischen Dichter Simias von Rhodos; die >Panflöte « wird Theokrit zugeschrieben. Als Verfasser der beiden Altar-Gedichte gelten der wenig bekannte Dosiadas von Kreta sowie ein nicht weiter zu identifizierender Dichter Besantinos. Siehe auch: Seraina Plotke: Selbstreferentialität im Zeichen der Bimedialität oder die Geburt einer Gattung. Visuelle Poesie aus hellenistischer Zeit. In: Arcadia. Internationale Zeitschrift für Literaturwissenschaft 40 (2005), S. 139-152; Irmgard Männlein-Robert: Stimme, Schrift und Bild. Zum Verhältnis der Künste in der hellenistischen Dichtung. Heidelberg 2007 (Bibliothek der klassischen Altertumswissenschaften N. F. Reihe 2; 119), S. 140-153.

8 Das 25. Kapitel des 2. Buchs der Poetices libri septem ist dem Umrissgedicht gewidmet (vgl. Julius Caesar Scaliger: Poetices libri septem. Sieben Bücher über die Dichtkunst. Hg. von Luc Deitz. Bd. 1. Stuttgart, Bad Cannstatt 1994, S. 555 f.). Neben dem auf die hellenistischen Vorbilder zurückgehenden Typus des Umrissgedichts existieren andere Macharten wie das Gittergedicht oder das Imago-Gedicht, die in der Spätantike und im Mittelalter entwickelt wurden und ebenfalls der Gattung der visuellen Poesie zugerechnet werden (dazu umfassend: Ulrich Ernst: Carmen figuratum. Geschichte des Figurengedichts von den antiken Ursprüngen bis zum Ausgang des Mittelalters. Köln, Weimar, Wien 1991).

9 Siehe Ulrich Ernst: Europäische Figurengedichte in Pyramidenform aus dem 16. und 17. Jahrhundert. Konstruktionsmodelle und Sinnbildfunktionen. Ansätze zu einer Typologie. In: Euphorion. Zeitschrift für Literaturgeschichte 76 (1982), S. 295-360 [wieder abgedruckt in: Ulrich Ernst: Intermedialität im europäischen Kulturzusammenhang. Beiträge zur Theorie und Geschichte der visuellen Lyrik. Berlin 2002 (Allgemeine Literaturwissenschaft - Wuppertaler Schriften; 4), S. 91-153]; Ulrich Ernst: Die neuzeitliche Rezeption des mittelalterlichen Figurengedichtes in Kreuzform. Präliminarien zur Geschichte eines textgraphischen Modells. In: Peter Wapnewski (Hg.): Mittelalter-Rezeption. Ein Symposium. Stuttgart 1986 (Göppinger Arbeiten zur Germanistik; 360), S. 177-233 [wieder abgedruckt in: Ernst: Intermedialität (Anm. 9), S. 181-223].

10 Das reiche Formenspektrum demonstrieren Adler, Ernst (Anm. 1), S. 44-194. 


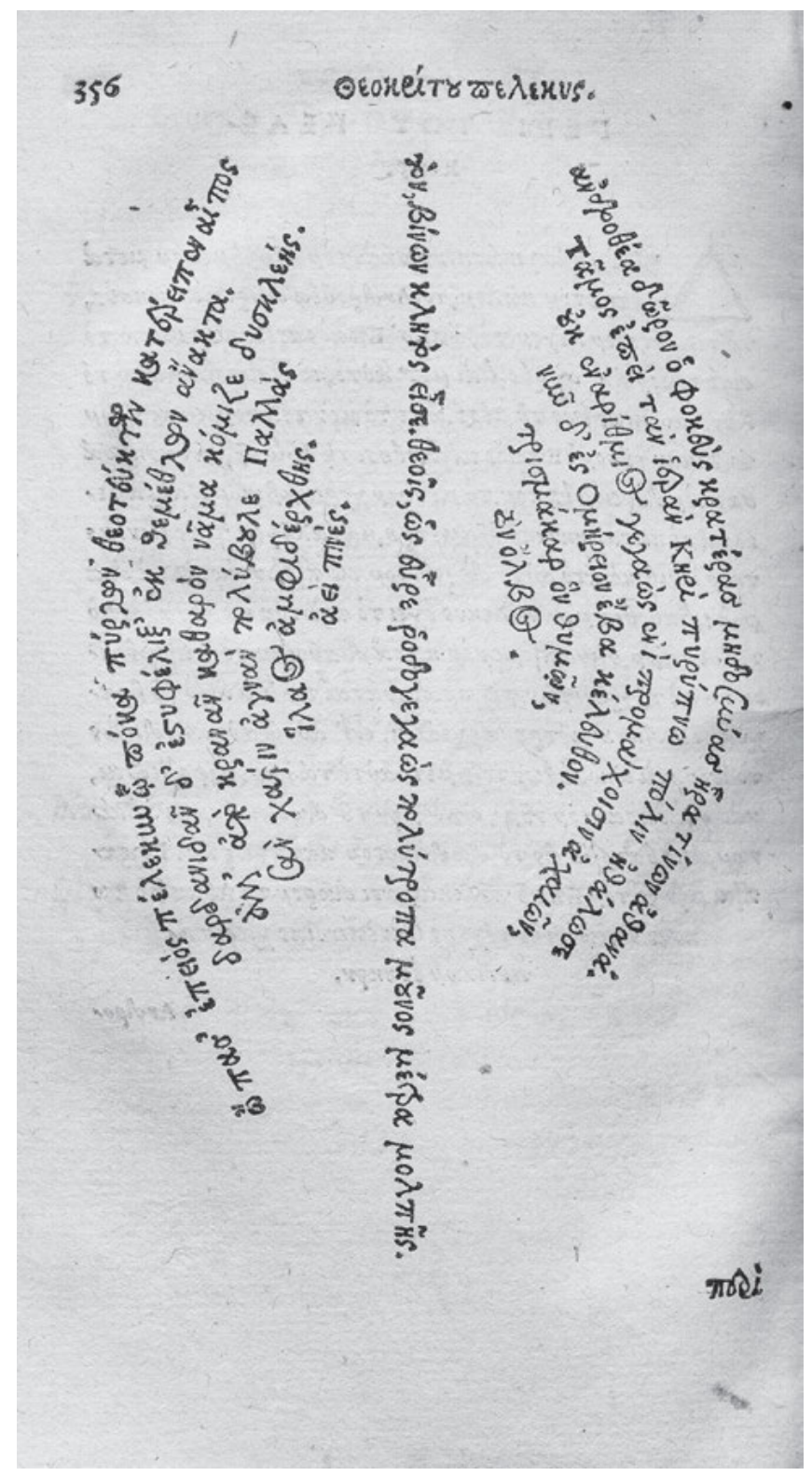

Abb. 1: [...] Theocriti Idyllia sex et triginta, cum scholijs in octodecim priora Zachariae Calliergi perquam utilius: et in fistulam, Ioannis Pediasmini: Annotatiunculisque in reliqua, Guilielmi Xylandri. Eiusdem Theocriti Epigrammata, Bipennis, et Ala. Per Petrum Brubachium, Francoforti [1558], S. 356 [Universitätsbibliothek Basel: Bc V 225:1]. Eine Analyse dieses Figurengedichts findet sich in: Plotke (Anm. 7), S. 148-152. 


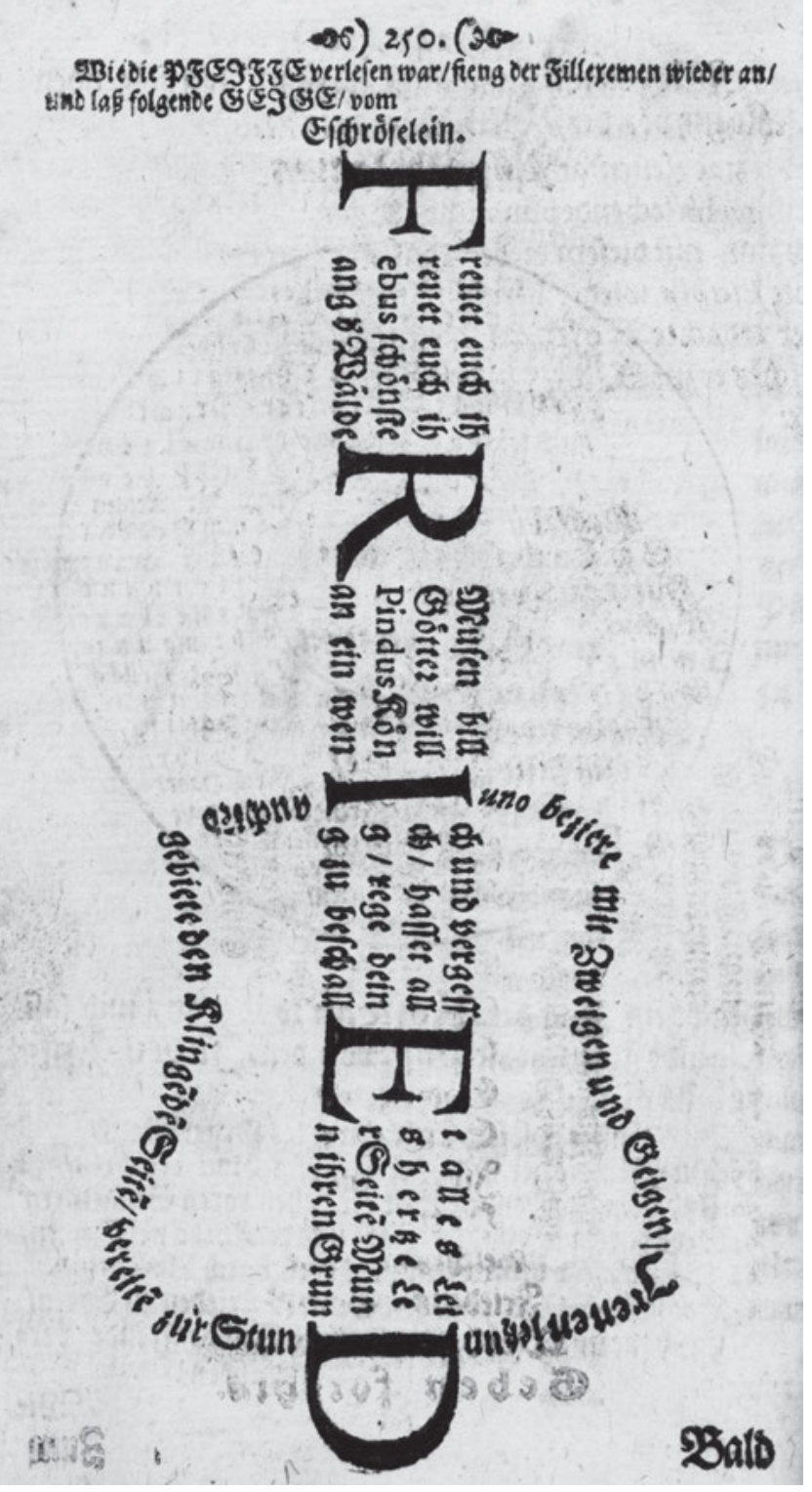

Abb. 2: Johann Geuder, Der Fried-seligen IRENEN Lustgarten, s. I. 1672, S. 250 [Universitätsbibliothek Basel: Am VI 58]. Eine Analyse dieses Figurengedichts findet sich in: Plotke (Anm. 3), S. 105-109. 


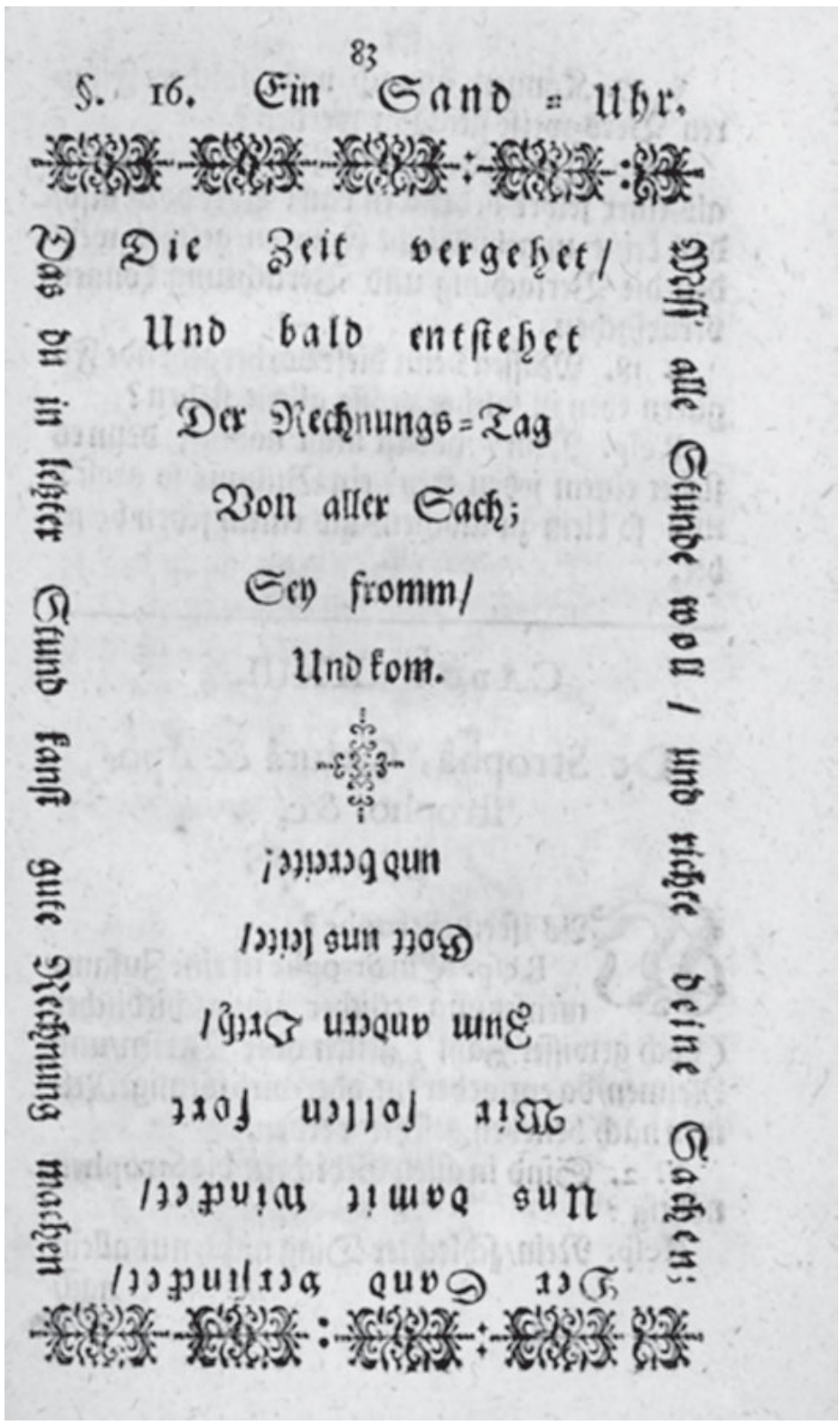

Abb. 3: Theodor Kornfeld, Selbst-Lehrende Alt-Neue Poesie Oder Vers-Kunst der Edlen Teutschen-Helden-Sprache, Bremen 1685, S. 83 [Universitätsbibliothek Rostock: Db-3030]. Eine Analyse dieses Figurengedichts findet sich in: Plotke (Anm. 3), S. 154-159. 


\section{enblitis gate \\ (D)ich swirb labets \\ Er aus Snaben \\ Ş is zur Engelídjat \\ Sets itbm bienftbar fornn \\ Dpffern $\mathfrak{B} D$ T \\ 3 um $B$ efangnen geben \\ Dich 'wirft biefer Şoff' utto brein \\ :/20rbinn in ber 23elt veritrt/: \\ Dap bu ver binden \\ Erfebn/ empinber \\ Bros 2 Bumber wirt \\ 230 Scers und Sinn \\ Sif oben binn \\ So glufft ber sauff \\ Şålt nichts bich) auff? \\ Jin berteranten Seelen. Furd)t uno 2 n g fit bich quelest \\ खืeñ Sủnben. \\ So madet frey \\ Die Aracney \\ Die Freแb und Suft \\ Darinn / uno alles: \\ 2uch felleft ber Schas \\ Er tff ber Tburm \\ Du Erben. 23urm! \\ 2n ЭES U flattre so citee \\ Die Dich zu GE fu ESTrifto trágt \\ Diecht Beten tft bie Eeiset \\ Du Erepp' if Dort fto on angelegs

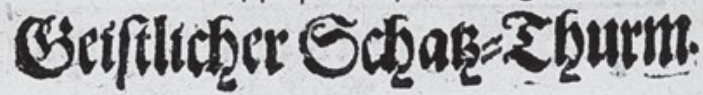

Abb. 4: Georg Weber, Sieben Theile Wohlriechender Lebens-Früchte, Danzig 1649, S. 58 [Herzog August Bibliothek Wolfenbüttel: TI 297]. Eine Analyse dieses Figurengedichts findet sich in: Plotke (Anm. 3), S. 231-235. 
Gerade im 17. Jahrhundert erlebte die Gattung eine erstaunliche Blüte, was mit einer Reihe von Faktoren in Zusammenhang zu bringen ist. ${ }^{11}$ So spielen mediengeschichtliche Gesichtspunkte eine Rolle, Aspekte des höfischen (und auf das Bürgertum ausgreifenden) Repräsentationswesens, im deutschsprachigen Bereich aber insbesondere auch Fragen der Etablierung des Deutschen als den klassischen Sprachen ebenbürtige Dichtersprache. Hand in Hand mit diesen kulturpragmatischen Faktoren beeinflussten spezifische vormoderne Denkmuster wie etwa die erst mit der Aufklärung modifizierte Vorstellung vom >Buch der Natur ${ }^{12}$ den Stellenwert der Gattung der Figurengedichte, die sich als Ausgangspunkt für die häusliche Frömmigkeit ähnlich gut eignete wie die im 17. Jahrhundert in viele Lebensbereiche vorgedrungene Emblematik (vgl. Abb. 5 u. 6).

Was die medientechnische Situierung der Gattung innerhalb der frühneuzeitlichen Druckkultur angeht, so ist grundsätzlich festzuhalten, dass dem Zusammenspiel von Text und Bild gerade im frühen Buchdruck ein besonders hoher Stellenwert zukam. Quasi von Anfang an wurde die Methode des mechanischen Gebrauchs beweglicher Lettern mit verschiedenen Verfahren des Bilddrucks kombiniert. Bereits die Vorform des Blockbuchs verknüpfte xylographisch Text und Bild und bot die Möglichkeit, reich illustrierte Bücher, wie sie im Spätmittelalter zunehmend an Bedeutung gewannen, in effizienterer Herstellung zu produzieren. In den auf die Gutenberg-Erfindung folgenden Dekaden führte der Einbezug von Holzschnitten oder Metallstichen in die Textausgaben dazu, dass sich mit Bildern illuminierte Drucke nicht nur für praktisch alle Textsorten finden, sondern aus der Verbindung des Letterndrucks mit Verfahren der Bildvervielfältigung insbesondere auch neue, spezifisch intermediale Gattungen - wie die Impresenkunst oder die schon genannte Emblematik - entstanden.

Dass das skizzierte reiche Spektrum an gedruckten Text-Bild-Konfigurationen einen fruchtbaren Nährboden für die wiederentdeckte hellenistische Gedichtform der Technopaegnien bildete, liegt auf der Hand. Im Gefolge der Experimentierfreudigkeit des prosperierenden Buchdrucks, der sich auf dem Feld publizistischer Neuschöpfungen wie dem Flugblatt besonders kreativ in Text und Bild ausdrückte, hatte auch eine Gattung wie die visuelle Poesie ihren Platz. Sie stellte, satztechnisch betrachtet, besonders hohe Ansprüche an die Offizinen, da ihre pikturale Komponente nicht - wie etwa bei den Emblemen - aus dem Einbezug bearbeiteter Holzblöcke oder gravierter Platten erfolgte, sondern durch die

11 Siehe weiterführend Plotke (Anm. 3).

12 Wie sich das auf das augustinische Gleichnis zurückgehende Vorstellungsbild des liber naturae über die Jahrhunderte veränderte, analysiert Hans Blumenberg: Die Lesbarkeit der Welt. Frankfurt a. M. 1979. 


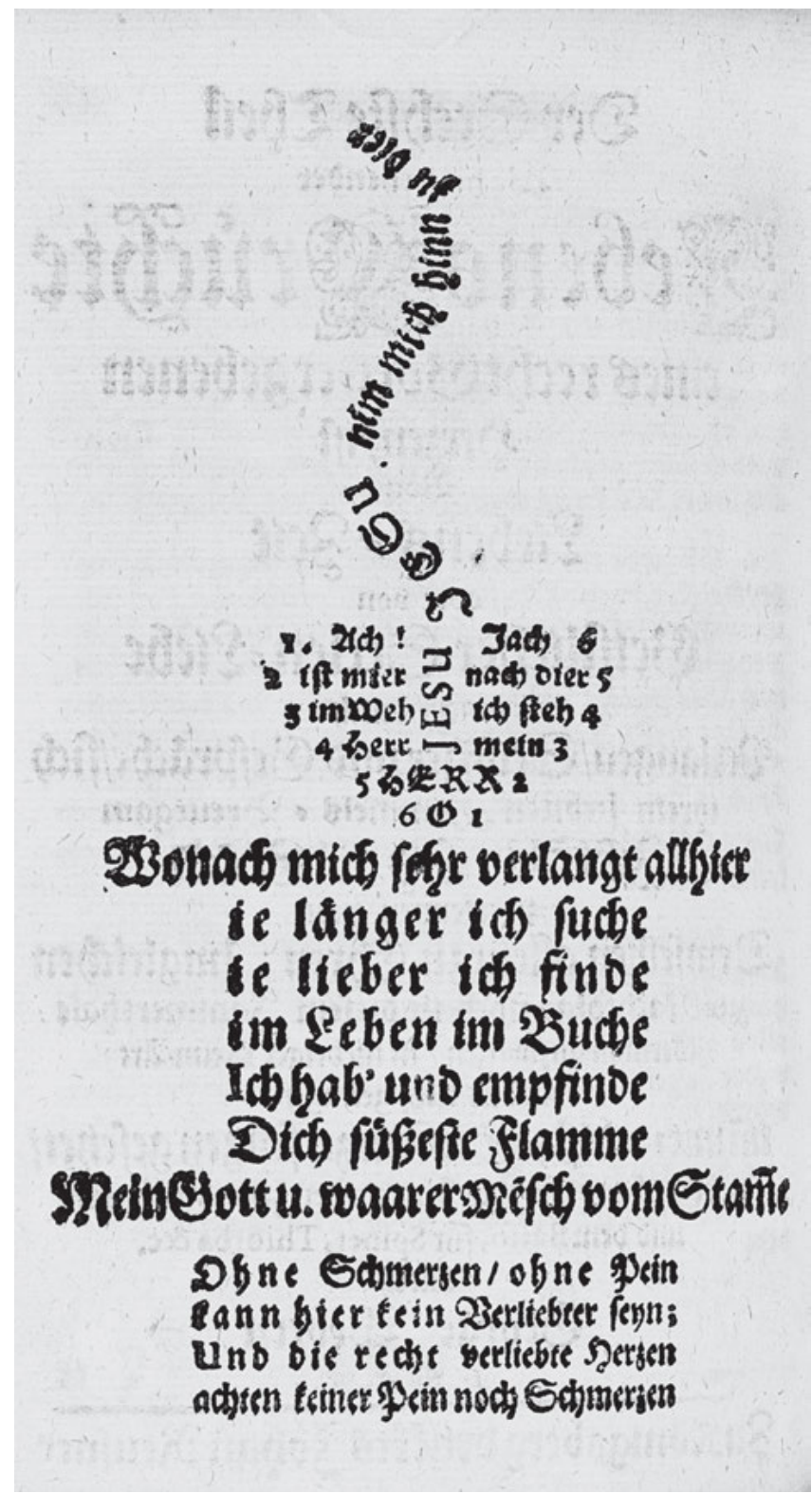

Abb. 5: Georg Weber, Sieben Theile Wohlriechender Lebens-Früchte, Danzig 1649, S. 376 [Herzog August Bibliothek Wolfenbüttel: TI 297]. Eine Analyse dieses Figurengedichts findet sich in: Plotke (Anm. 3), S. 250-257. 


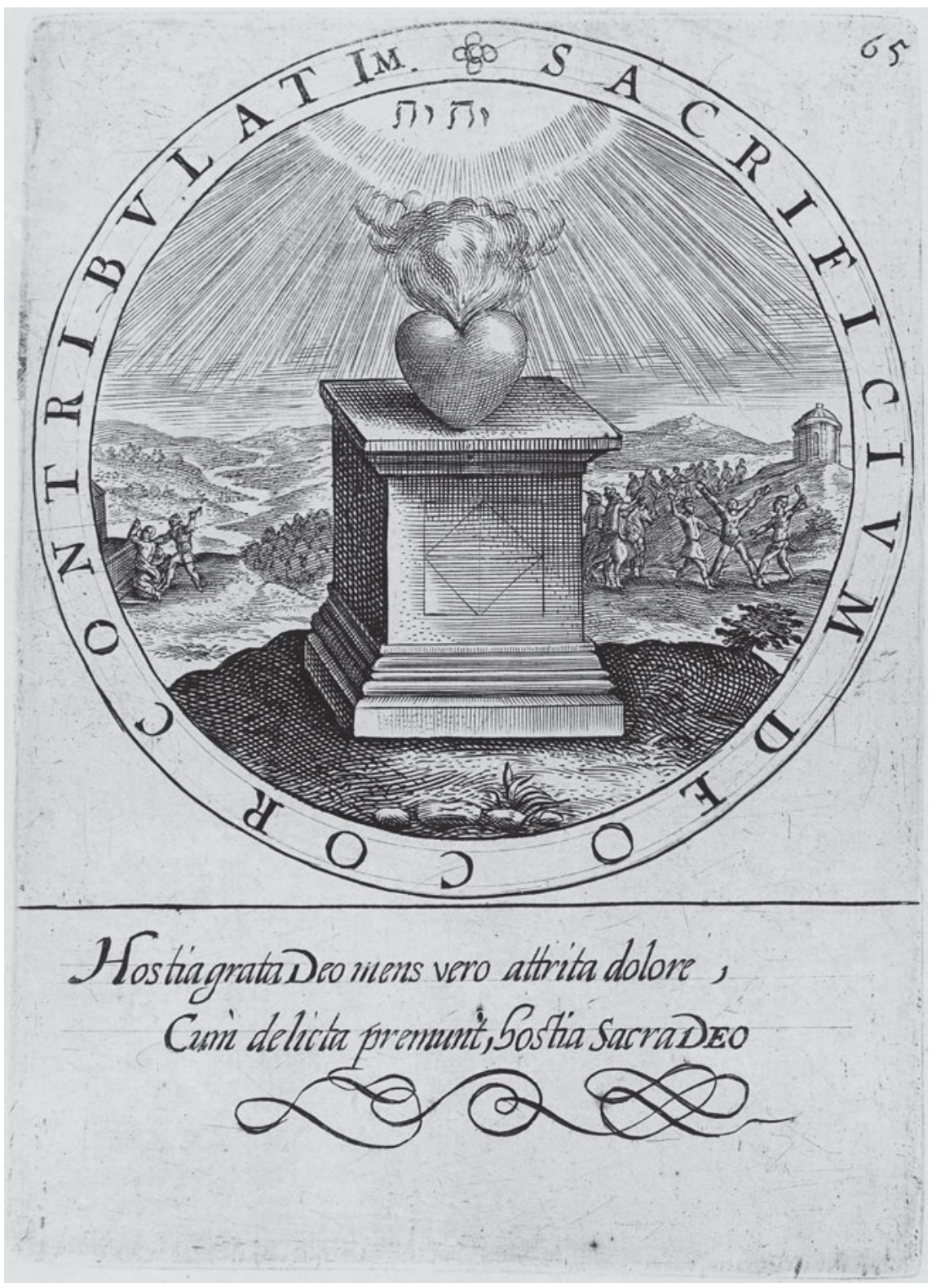

Abb. 6: Gabriel Rollenhagen, Nucleus emblematum selectissimorum, Utrecht 1611, S. 65 [Herzog August Bibliothek Wolfenbüttel: A: 21.2 Eth. (1)]. 
figurative Anordnung der Einzellettern selbst, was dem Drucker entsprechende handwerkliche Fertigkeiten abverlangte.

Im Dialog mit den vielgestaltigen intermedialen Erscheinungsformen der damaligen Druckkultur unterbreiten zeitgenössische Traktate, Poetiken, Vorreden zu Emblembüchern usw. auch ausführliche kunsttheoretische Überlegungen, die Dichter wie bildende Künstler über das Verhältnis von Text und Bild anstellten. ${ }^{13}$ Programmatisch wird dabei die Vergleichbarkeit der beiden Ausdrucksarten behauptet, in der Regel im Rekurs auf die ut pictura poesis-Formel des Horaz oder das Diktum des Simonides von Keos, Malerei sei schweigende Dichtung und Dichtung beredte Malerei. ${ }^{14} \mathrm{Im}$ 17. Jahrhundert thematisieren gerade auch die deutschsprachigen Poetiken den Gedanken der Verwandtschaft der beiden Künste immer wieder, setzen diesen in Beziehung zur allegorischen Bildlichkeit, zur Gattung der Emblematik oder auch zur visuellen Poesie, wie beispielsweise Johann Christoph Männling in seiner 1685 erschienenen Poetik Der Europaeische Parnassus. Männling greift den Vergleich der Dichtkunst mit der Malerei im Zusammenhang seiner Charakterisierung der Figurengedichte auf, die er - wie in den deutschen Lehrschriften der Zeit üblich - als Bilder-Reime bezeichnet:

Bilder-Reime / so die Frantzosen Accolade nennen / welche recht die Mahlerey der Poeten können heissen / sind diejenigen / welche der Natur nachgehen / und eine Sache gleichsam lebendig / oder wie sie beschaffen ist / vorstellen. Unter die Bilder-Reime werden gerechnet: Ein Hertze / Ey / Creutz / Becher / Blumkrug / Spiegel / Stern / Rose / Tulipan / Narcisse / Baum / Pyramide / Apffel / und dergleichen / welche Sachen alle durch die Verße also müssen abgemahlet werden / daß sie eben daßjenige praesentieren was man will haben $[. ..] .^{15}$

Männling modifiziert den Topos von der Ähnlichkeit der beiden Künste in der Weise, dass er nicht, wie üblich, allegorische Bildlichkeit oder rhetorisches ,VorAugen-Stellen` als »die Mahlerey der Poeten« bezeichnet, sondern die der visuellen Poesie eigene figurative Anordnung der Wörter.

13 Siehe etwa Gottfried Willems: Anschaulichkeit. Zu Theorie und Geschichte der Wort-Bild-Beziehungen und des literarischen Darstellungsstils. Tübingen 1989; Bernhard F. Scholz: Emblem und Emblempoetik. Historische und systematische Studien. Berlin 2002 (Allgemeine Literaturwissenschaft - Wuppertaler Schriften; 3), S. 43-230.

14 Rhetorica ad Herennium, IV, 39: Poema loquens pictura, pictura tacitum poema debet esse (zitiert nach der Ausgabe: Rhetorica ad C. Herennium. De Ratione Dicendi. Lateinisch-deutsch. Hg. und übers. von Theodor Nüßlein. Darmstadt 1994). Vgl. dazu Plotke (Anm. 3), S. 111-125.

15 Johann Christoph Männling: Europaeische Parnassus, Oder Kurtze und deutliche Anweisung zu der Deutschen Dicht-Kunst [...]. Wittenberg 1685, S. 84 (im Kapitel »Von den Arten der Verße«, unter dem Punkt »Die 13. Art. Bilder-Reime«). 
Dass Johann Christoph Männling den Figurengedichten im Europaeischen Parnassus einen eigenen Paragraphen einräumt, ist charakteristisch für die poetologischen Lehrschriften seiner Zeit. Nachdem Philipp von Zesen die Gattung 1640 in seinen Deutschen Helicon aufgenommen hatte, ${ }^{16}$ fehlten die Bilder-Reime oder Bild-Gebände, wie sie auch genannt wurden, in kaum einer der normativen Poetiken der folgenden Dekaden. ${ }^{17}$ Zwar gab es, insbesondere gegen Ende des Jahrhunderts, auch kritische Stimmen, die das Genre als simple Spielerei abtaten, doch wurde die visuelle Poesie in bestimmten Literatenzirkeln gerade speziell geschätzt, so etwa im Umkreis der Pegnitz-Schäfer in Nürnberg, für die die Gattung aufgrund ihrer hellenistischen Ursprünge unmittelbar mit der Bukolik verknüpft war. ${ }^{18}$ Durch die komplexe verstechnische Struktur waren die Figurengedichte besonders geeignet, die Befähigung des Deutschen zur Dichtersprache nach antikem Muster zu demonstrieren.

Ihre weitaus größte Ausbreitung erlebte die visuelle Poesie im 17. Jahrhundert allerdings im Bereich der Casuallyrik. Nicht nur im Rahmen der höfischen Festkultur, sondern auch anlässlich bürgerlicher Hochzeiten und Todesfälle wurden Bilder-Reime mit Glückwünschen oder Kondolenzbekundungen dediziert. ${ }^{19}$ Dass die Verknüpfung von visueller Poesie und Gelegenheitsdichtung sich als äußerst fruchtbar erwies, spiegelt sich in der Quantität der überlieferten Texte, vor allem aber in den Poetiken wider. So beschreibt Johann Heinrich Hadewig im Kapitel »Von Hochzeit- und anderen Ehren- und Glückwünschungs-Getichten« seiner 1650 veröffentlichten Lehrschrift Kurtze und richtige Anleitung / Wie in unser Teutschen Muttersprache Ein Teutsches Getichte zierlich und ohne Fehler könne verfertiget werden das mögliche Anwendungsfeld der Figurengedichte wie folgt:

\footnotetext{
Weil man auf Hochzeiten mit Trinkgeschirren ümgehet / und zwischen Braut und Bräutigam eine hertzbrünstige Liebe erspüret wird: würde es nicht übel stehen / wan ein Pocal oder Hertze in gewisse Verse verfasset und getichtet würde. ${ }^{20}$
}

16 Vgl. Philipp von Zesen: Sämtliche Werke. Hg. von Ferdinand van Ingen. Unter Mitw. von Ulrich Maché und Volker Meid. Berlin, New York 1971-2003. Bd. 9 (Ausgaben deutscher Literatur des XV. bis XVIII. Jahrhunderts; 25), S. 335, 341-344.

17 Siehe Plotke (Anm. 3), S. 20-28; Adler, Ernst (Anm. 1), S. 73-86.

18 Vgl. Adler, Ernst (Anm. 1), S. 154-167; Jeremy Adler: Pastoral Typography. Sigmund von Birken and the >Picture-Rhymes` of Johann Helwig. In: Visible Language 10/1 (1986), S. 121-135; Plotke (Anm. 3), S. 94-109.

19 Vgl. Plotke (Anm. 3), S. 183-202; Adler, Ernst (Anm. 1), S. 183--194.

20 Johann Heinrich Hadewig: Kurtze und richtige Anleitung / Wie in unser Teutschen Muttersprache Ein Teutsches Getichte zierlich und ohne Fehler könne verfertiget werden [...]. Rinteln 1650, S. $163 \mathrm{f}$. 
Aufgrund ihrer aufwändigen Machart waren Figurengedichte besonders gut geeignet, um der im Zentrum der Feierlichkeiten stehenden Person die Ehre zu erweisen. Dazu kam, dass sich über das gewählte pikturale Motiv bereits ein thematischer Bezug zum betreffenden Festakt herstellen ließ, wie Hadewig in seiner Poetik gerade hervorhebt. Das spielerische Moment, das den Figurengedichten aufgrund der Sistierung konventioneller Lesevorgänge genretypisch anhaftete und das den Gebilden mitunter den Charakter eines Rätsels verlieh, diente bei heiteren Anlässen der Unterhaltung der Festgesellschaft.

Derartige Rätsel-Gedichte machten sich denn auch zu Nutze, was bei der Rezeption von Figurengedichten generell gilt: Der gewohnheitsmäßige Leseprozess ist aufgehoben, da die Bild-Gestalt der Verse für einen ersten Blickfang sorgt, so dass erst in einem zweiten Schritt mit der Lektüre des diskursiven Texts begonnen werden kann. Weil in der visuellen Poesie Literalität und Pikturalität in eins gesetzt sind, streng genommen also dasselbe Zeichen in verschiedenen Zeichenfunktionen oder eben Signifikationsmodi decodiert werden muss, ist die Rezeption in ihrem Verlauf durch ein ständiges Oszillieren zwischen Bild-Sehen und Text-Lesen geprägt. Allein dadurch ergibt sich eine Retardation und Entautomatisierung des Lesevorgangs, was sich in unterschiedlichen Kontexten je anders nutzbar machen ließ: Während die Bilder-Reime bei festlichen Gesellschaften als knifflige Leseaufgaben zum Amusement der Anwesenden beizutragen vermochten, ging die Verlangsamung des Lektüreakts bei Figurengedichten mit erbaulichem Gehalt, die für die häusliche Andacht konzipiert waren, Hand in Hand mit der gewünschten kontemplativen Haltung und der meditativen Versenkung in das Textgebilde. ${ }^{21}$

Zur gattungskonstitutiven Aufhebung etablierter Lesekonventionen, die zu einem freien Hin und Her zwischen differenten Wahrnehmungsarten zwingt, kommt in vielen Bilder-Reimen die Suche nach der sinnvollen Reihenfolge der Verse dazu, die nicht zwangsläufig der üblichen von oben nach unten entspricht, sondern gerade umgekehrt sein kann, so dass die Lektüre eine aufsteigende Bewegung oder auch eine Art Bauprozess vollzieht; in einigen Fällen wird sogar erfordert, dass das Blatt zur Entzifferung des Sinngehalts mehrfach gedreht und rotiert wird. Die oft komplexe Struktur der Figurierung führt dazu, dass im Sinne

21 Diesen Fokus auf die Gattung wählt beispielsweise Sigmund von Birken in seiner Poetik Teutsche Rede- bind- und Dicht-Kunst, indem er ein Gedicht in Kreuzform als Beispielgedicht präsentiert und dazu folgenden Aufruf an die Rezipienten formuliert: „Wer seinen Jesum recht kennet und liebet / wird neben-stehendem Creuz noch viele nachmachen / auch dergleichen mit der DornKrone der Geisel-Seule / und andrem unsers theuren Heilands Passion-Zeug / ersinnen können « (Siegmund von Birken: Deutsche Rede- bind- und Dicht-Kunst. Nachdruck der Ausgabe Nürnberg 1679. Hildesheim, New York 1973, S. 144). 
eines trial-and-error-Verfahrens allererst eruiert werden muss, wo mit der Lektüre des diskursiven Texts zu beginnen ist.

Der hermeneutische Zirkel zeichnet sich in den Bilder-Reimen denn auch meist dadurch aus, dass bereits die Figurierung der Verse einen ersten Sinnentwurf ermöglicht, von dem aus über die Mehrfachlektüre der einzelnen Zeilenpassagen tiefer in die Bedeutung der Text-Bild-Konfiguration als Ganzer eingedrungen wird, indem der Worttext des Gedichts immer wieder von neuem in ein Verhältnis zur Bildebene gesetzt wird. Dabei wird nicht nur der mittels der pikturalen Decodierung gewonnene semantische Erstbefund revidiert und modifiziert, sondern es erhält bisweilen auch die Dynamik des Rezeptionsprozesses eine signifikationsstiftende Funktion; so bekommen sogar einzelne Wörter aufgrund ihres Platzes innerhalb der Figur einen spezifischen Gehalt.

Um die Mechanismen, wie sie sich im intermedialen Spiel frühneuzeitlicher visueller Poesie ergeben, zu beleuchten, seien im Folgenden zwei Figurengedichte des Frankfurter Dichters Johann Rudolf Karst genauer betrachtet, die dieser 1667 in seinem Deutscher Dicht-Kunst Lust- und Schau-Platz veröffentlichte. Der Band besteht aus fünf thematisch geordneten Sammlungen von Gelegenheitsgedichten, die Karst im Verlauf der vorausgegangenen Jahre für adlige und bürgerliche Widmungsträger verfasst hatte. ${ }^{22}$ Dass Casualcarmina allgemein zur dichterischen Praxis der damaligen Epoche gehörten, ${ }^{23}$ belegt neben der schieren Masse an Gelegenheitsgedichten aus dem 17. Jahrhundert auch die Existenz von Poetiken, die sich ausschließlich dem Thema der Casuallyrik widmen. ${ }^{24}$ Selbst in

22 Der vollständige Titel des Bands lautet: Johann Rudolf Karstens Deutscher Dicht-Kunst Lustund Schau-Platz. Darinnen zu finden I. Etliche sonderbahre / hohen Stands-Personen zu tieffschuldigsten Ehren / verfertigte Freuden- und Glükkwünschungs-Gedichte. II. Der weltberuffenen Statt Frankkfurt am Meyn neugebundener Lorbeer-Krantz. III. Zwey Dutzet anmüthige / mit feinen Kunst-Stükken und artig-gefügten Bilder-Reimen beschlossene Neu-Jahrs-Gedichte. IV. Allerhand lustige Hochzeit- und Freuden-Gedichte / wobey gleichfalls einige zuvor in Teutscher Spraach nie gesehene Kunst-Stükk zu beobachten / sampt nützlicher Einführung feiner geist- und weltlicher Rätsel / wie nicht weniger underschiedliche Klag-Schallmeyen und TrauerZimbeln. V. Fünffzehen schöner Ehrenbinde / in welchen etlicher vornehmer Heiligen Christlichgeführter Handel und Wandel / Leben und Todt in lieblicher Zierde besungen und vorgestellet wird. Frankkfurt am Mayn / Jn Verlegung Wilhelm Serlins. Jm Jahr MDCLXVII.

23 Grundlegend zur Casuallyrik Wulf Segebrecht: Das Gelegenheitsgedicht. Ein Beitrag zur Geschichte und Poetik der deutschen Lyrik. Stuttgart 1977.

24 Zum Beispiel: Balthasar Kindermann: Der Deutsche Poet / Darinnen gantz deutlich und ausführlich gelehret wird / welcher gestalt ein zierliches Gedicht / auf allerley Begebenheiten / [...] kan wol erfunden und ausgeputzet werden / [...]. Wittenberg 1664. Reprint Hildesheim, New York 1973. Häufig wurden die Gelegenheitsgedichte in den Poetiken auch typenweise besprochen. Magnus Daniel Omeis beispielsweise handelt in seiner Gründlichen Anleitung Zur Teutschen accuraten Reim- und Dichtkunst die folgenden Gedichttypen einzeln ab: »Geburts-Gedichte«, 
den weniger spezifischen Lehrschriften verwendeten viele Poetologen zur Exemplifizierung einer bestimmten dichterischen Form Beispiele, die sie ursprünglich anlassgebunden verfasst hatten. ${ }^{25}$ Darüber hinaus waren Sammelausgaben von Casuallyrik wie diejenige Karsts, in denen einzelne Literaten ihre zu unterschiedlichen Ereignissen geschaffenen Gelegenheitsgedichte im Verbund publizierten, gut etabliert und sehr beliebt.

Karsts Deutscher Dicht-Kunst Lust- und Schau-Platz präsentiert die vereinigten Gedichte im Wesentlichen nach Anlässen gegliedert, darunter Neujahrs-, Hochzeit- und Trauergedichte. Der Band zeichnet sich dadurch aus, dass er insgesamt über dreißig Figurengedichte enthält. Diese finden sich in allen fünf Teilen der Sammlung, auch wenn es im dritten eine Ballung gibt, wie schon die Inhaltsangabe im Untertitel des Werks verdeutlicht, indem sie ankündigt: III. Zwey Dutzet anmüthige / mit feinen Kunst-Stükken und artig-gefügten Bilder-Reimen beschlossene Neu-Jahrs-Gedichte. Bemerkenswert hinsichtlich der Einschätzung der visuellen Poesie im 17. Jahrhundert ist die diesen dritten Teil einleitende, an den »Deutschliebende[n] / hochgeneigte[n] / klug-sinnige[n] Leser « gerichtete Vorrede des Dichters. ${ }^{26}$ Mit Blick auf die »Kunst-gefügten Reimen-Bilder[]« erklärt Karst hier, er habe diese »nicht zu [s]einer / sondern zuforderst $\mathrm{zu}$ deß allein weisen und unsterblichen Himmels-Königs / und dann zu unsers lieben Vatterlandes und der deutschen Sprach Ehre verfertiget «. ${ }^{27}$ Der Dichter legt damit nicht nur klar, dass er seine Figurengedichte in den Kontext christlicher Erbauung stellt, sondern macht auch den Gedanken stark, die aufwändige Machart der

»Namens-Tag-Gedichte«, »Lob-Gedichte«, »Dank-Gedichte«, »Hochzeit-Gedichte«, »Sieg-Glückwünschung «, »Leich-Gedichte« (vgl. Magnus Daniel Omeis: Gründliche Anleitung Zur Teutschen accuraten Reim- und Dichtkunst. Nürnberg 21712, S. 151-180).

25 Mit Blick auf die visuelle Poesie ist die Poetik Theodor Kornfelds ein markantes Beispiel hierfür: Zur Exemplifizierung der Gattung der Figurengedichte führt Kornfeld fünfzehn Musterstücke an, darunter sieben Casualcarmina, die er nach eigenen Angaben zu früheren Zeiten anlässlich entsprechender Gelegenheiten (Hochzeiten, Siegerehrungen etc.) verfasst hatte und in seiner Poetik erneut zum Druck brachte (vgl. Theodor Kornfeld: Selbst-Lehrende Alt-Neue Poesie Oder Vers-Kunst der Edlen Teutschen-Helden-Sprache. Bremen 1685, S. 69-83). Auch andere Poetologen haben ehemals produzierte Gelegenheitsgedichte genommen, um sie als Beispiele für die Bilder-Reime in ihre Poetiken zu setzen, so etwa Albrecht Christian Rotth, Johann Hoffmann oder Johann Christoph Männling (Albrecht Christian Rotth: Vollständige Deutsche Poesie 1688. Hg. von Rosmarie Zeller. 1. Teilbd. Tübingen 2000 (Deutsche Neudrucke. Reihe Barock; 41), S. 119; Johann Hoffmann: Lehr-mässige Anweisung zu der Teutschen Verß- und Ticht-Kunst. Nürnberg 1702, T. III, S. 106; Männling (Anm. 15), S. 85).

26 Karst (Anm. 22), S. 28.

27 Ebd. 
Texte, die dem Verfasser einiges verskünstlerische Geschick abverlangt, adele die deutsche Sprache als Dichtersprache.

Das erste der beiden Gedichte, die ich nun eingehender betrachten möchte, ist Johann Georg Fabricius, Pfarrer zu Oberwiddersheim, sowie dessen Gattin gewidmet und auf das Jahr 1663 datiert. Es gehört in die Sammlung der Neujahrsgedichte und wird eingeleitet durch rund sechzig Alexandriner, die in die Thematik des Jahreswechsels einführen und zugleich die Dedikanden als »Freunde Paar« apostrophieren. ${ }^{28}$ Das Figurengedicht selbst trägt den Titel (Abb. 7): »Der wahren Freundschafft Ehren-Seul. Syrach. 6. ${ }^{29}$ Nicht nur aufgrund dieser Überschrift, sondern auch durch die markante Figurierung der Verse lässt sich der dargestellte Umriss bereits beim ersten Augenschein als Säule interpretieren und erinnert damit an die Triumphsäulen, die schon im alten Rom zu Ehren siegreicher Feldherren aufgestellt wurden.

Als Prototyp antiker Siegessäulen darf die mit einem Reliefband verzierte Trajanssäule gelten, die - wie die ungeschmückten Ehrensäulen und die Triumphbögen auch - eigentlich als Sockel für die Statue des betreffenden Heerführers diente. Über die aktuelle Glorifizierung des Feldherrn hinaus dienten derartige Siegessäulen als Erinnerungsmal: Das Monument verherrlicht die Taten des Heerführers zum einen in der Festsituation des Triumphzugs, zeigt diese zum anderen aber auch späteren Generationen an. Der Leser des 17. Jahrhunderts kannte die antike Sitte, erfolgreichen Generälen Ehrensäulen oder Triumphbögen zu errichten, nicht nur aus der Literatur, von Skizzen oder Kupferstichen: ${ }^{30}$ Die Gepflo-

\section{Ebd., S. 68. \\ 29 Ebd., S. 70.}

30 Heute noch erhaltene Skizzen der Trajanssäule beispielsweise von Giovannantonio Dosio (1569, Federzeichnung), Etienne du Pérac (1575, Mischtechnik), Gillis van Valckenborch (1590, Mischtechnik), der Säule des Marc Aurel von Dosio (um 1580, Federzeichnung); Abbildungen in: Hermann Egger (Hg.): Römische Veluten. Handzeichnungen aus dem XV. bis XVIII. Jahrhundert zur Topographie der Stadt Rom. 2. Bd. Wien 1931, Tafeln 45 und 76; James E. Packer: The Forum of Trajan in Rome. A Study of the Monuments. Bd. 1. Berkeley, Los Angeles, Oxford 1997 (California studies in the history of art; 31), S. $26 \mathrm{f}$. Die antiken Monumente konnten zudem auch von Italienreisenden vor Ort bewundert werden. Neben den Pilgern, wie sie zu allen Zeiten Rom aufsuchten, müssen hier die englischen, französischen und deutschen Studenten genannt werden, die sich gern an italienischen Universitäten einschrieben. Des Weiteren begannen bereits im 17. Jahrhundert die Söhne aus gutem Hause Bildungsreisen in die Ewige Stadt zu unternehmen (vgl. etwa Attilio Brilli: Als Reisen eine Kunst war. Vom Beginn des modernen Tourismus: Die »Grand Tour«. Berlin 1997 (Wagenbachs Taschenbuch; 274), S. 14-17). Zahlreiche Reisebeschreibungen belegen die rege Reisetätigkeit jener Zeit (Beispiele aus dem späten 16. und dem 17. Jahrhundert präsentiert Dorothea Kuhn: Auch ich in Arcadien. Kunstreisen nach Italien 1600-1900. Stuttgart 1966 (Sonderausstellung des Schiller-Nationalmuseums; 16), S. 10-36; Lucia Tresoldi: Viaggiatori Tedeschi In Italia 1452-1870. Bd. 1. Rom 1975, S. 11-40). 


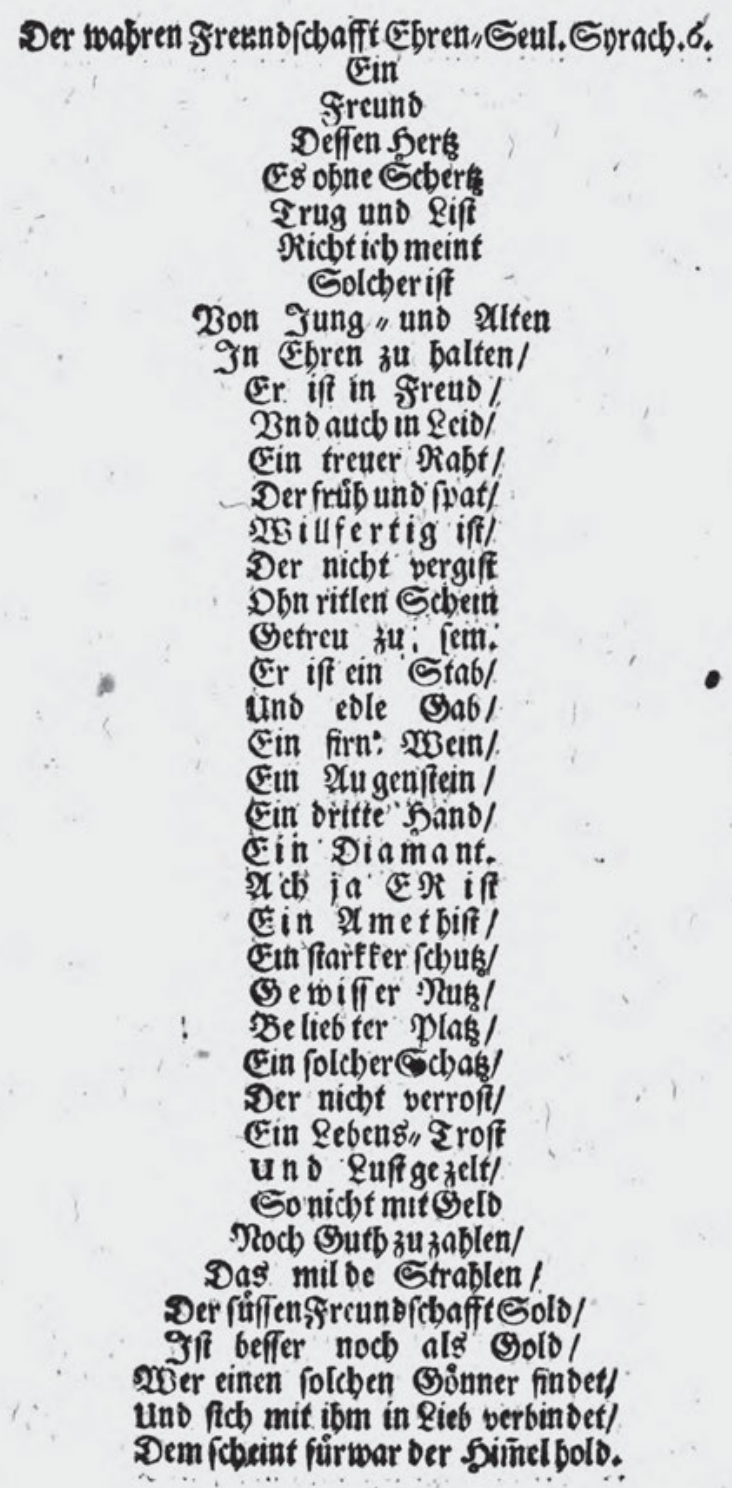

Abb. 7: Johann Rudolf Karst, Deutscher Dicht-Kunst Lust- und Schau-Platz, Frankfurt a. M. 1667, S. 70 [Bayerische Staatsbibliothek: P.o.germ. 707 k]. 
genheit wurde in der italienischen Renaissance wieder aufgenommen ${ }^{31}$ und entwickelte sich insofern weiter, als temporär aufgebaute Säulen und Bögen zu zentralen Elementen der barocken Festarchitektur avancierten. ${ }^{32}$ Darüber hinaus wurde Säulenmonumenten gerade in der Kunst der frühen Neuzeit ein reicher Symbolgehalt zuerkannt: Gemäß den verbreiteten Allegoriewörterbüchern ist die Säule Sinnbild für Festigkeit und Beständigkeit, verkörpert Hoffnung, Tapferkeit und Stärke. ${ }^{33}$ Was die visuelle Poesie der Zeit angeht, war das Säulenmotiv, wohl nicht zuletzt wegen dieses Sinngehalts, ein beliebtes Sujet. ${ }^{34}$

Die meisten der genannten Bedeutungsaspekte wird die damalige Rezipien$\operatorname{tin}^{35}$ der Gedicht-Säule schon bei der ersten Wahrnehmung zugeordnet haben. Bereits die vorausgehenden Alexandriner sowie die Gedichtüberschrift lenken diesen Sinnhorizont jedoch in eine spezifische Richtung. So ist es nicht ein siegreicher Feldherr, dem hier ein Ehren- und Erinnerungsmal errichtet ist, sondern die Freundschaft, die aufgrund des Symbolgehalts der Figur in ihrer Festigkeit und Stärke ausgezeichnet wird. ${ }^{36}$ Die Freundschaft ist es, der die Säule aus Versen gewidmet ist, sie steht an der Spitze des Monuments - ein Sinnentwurf, der sich mit den ersten Worten des Verstexts vollends bestätigt: Zuoberst und mittig auf der Säule platziert sind nämlich die Wörter »Ein Freund «. Der Freund, quasi als Personifikation der Freundschaft, prangt damit - wie die Statue des sieghaften Heerführers - über dem Säulenschaft. Er und sein »Hertz«, wie es in der dritten

31 Vgl. Werner Haftmann: Das italienische Säulenmonument. Versuch zur Geschichte einer antiken Form des Denkmals und Kultmonuments und ihrer Wirksamkeit für die Antikenvorstellung des Mittelalters und für die Ausbildung des öffentlichen Denkmals in der Frührenaissance. Leipzig, Berlin 1939 (Beiträge zur Kulturgeschichte des Mittelalters und der Renaissance; 55), S. 151. 32 In der Festarchitektur fiel der Aspekt des materiellen Erinnerungsmals aufgrund der Ephemerität des Festakts allerdings weg. Die erinnerungsstiftende Funktion übernahmen hier die Festberichte, die solche Ehrensäulen häufig in Kupferstichen zeigen (siehe zu den Funktionen der Festberichte Thomas Rahn: Fortsetzung des Festes mit anderen Mitteln. Gattungsbeobachtungen zu hessischen Hochzeitsberichten. In: Jörg Jochen Berns, Detlef Ignasiak (Hgg.): Frühneuzeitliche Hofkultur in Hessen und Thüringen. Erlangen, Jena 1993 (Jenaer Studien; 1), S. 233-248).

33 Siehe beispielsweise Hieronymus Lauretus: Silva allegoriarum totius sacrae scripturae. Barcelona 1570. Fotomechanischer Nachdruck der zehnten Ausgabe Köln 1681. Hg. von Friedrich Ohly. München 1971, S. 257.

34 Vgl. Plotke (Anm. 3), S. 176-183; Adler, Ernst (Anm. 1), S. 87-101.

35 Nicht nur um der politischen Korrektheit willen, sondern auch, weil im 17. Jahrhundert der Anteil des weiblichen Lesepublikums eine markante Größe darstellte, verwende ich im Folgenden abwechselnd weibliche und männliche Formen.

36 Auch der Zusatz »Syrach.6. « weist dezidiert auf das Thema der Freundschaft hin: Im Buch Jesus Sirach, Kapitel 6, geht es um wahre und falsche Freundschaft. 
Zeile heißt, werden in der gerundeten Gestalt der Verse im Oszillieren zwischen dem pikturalen und dem diskursiven Signifikationsmodus sichtbar.

Mit der voranschreitenden Lektüre des Säulen-Gedichts eröffnen sich dem Leser weitere Charakteristika wahrer Freundschaft, indem die Verse benennen, was einen Freund als solchen auszeichnet: Dieser ist in jeder Lebenssituation »Ein treuer Raht«, er ist »Willfertig" und »Getreu«. Es folgen Sprachbilder, die das Wesen eines Freundes in überhöhender Weise veranschaulichen, wobei die Aufhäufung von Edelstein-Metaphern, die das wertvolle Strahlen betonen, heraussticht. So wird über die Bestimmungen des Freundes als »Augenstein«, »Diamant« und »Amethist" die besondere Kostbarkeit und Seltenheit echter Freundschaft hervorgehoben. Geradezu analog zu den Reliefbändern antiker Siegessäulen, die die militärischen Leistungen des geehrten Feldherrn entlang des Säulenschafts abbilden, illustrieren hier die metaphorischen Charakterisierungen die >Heldenhaftigkeit $`$ wahrer Freundschaft. Aufgrund der Positionierung der betreffenden Wörter als Bauteile der Schafttrommel werden die Merkmale und Qualitäten eines Freundes gleichzeitig aber auch zu funkelnden Steinen des Schmucks an der Ehren-Säule.

Der Verstext endet in der Säulenbasis mit der maximenartigen Erkenntnis, dass der - gerade nicht mit Gold aufzuwiegende - Schatz eines »solchen Gönner[s]« für denjenigen, der ihn »findet / | Und sich mit ihm in Lieb verbindet«, echtes Himmelsglück bedeutet. Im Lob des Freundschaftssegens steckt hier auch die Aufforderung, sich selbst einen entsprechenden Verbündeten zu suchen. Es wird nicht zuletzt an dieser Stelle deutlich, dass das Säulen-Gedicht im Grunde genommen eine emblematische Struktur besitzt. Gemäß Albrecht Schöne korrespondiert mit dem meist dreiteiligen Aufbau eines Emblems die »Doppelfunktion des Abbildens und Auslegens oder des Darstellens und Deutens«, wobei die Pictura auch der Ausdeutung dienen kann, Motto und Subscriptio auch an der Abbildung teilhaben können. ${ }^{37}$ Zudem zeichnen sich Embleme dadurch aus, dass mit der Ausdeutung der res significans der Aufruf zur Befolgung bestimmter Verhaltensmaximen verknüpft ist. ${ }^{38}$ Auch Karsts Figurengedicht besitzt Motto, Pictura und Subscriptio, wobei sich die Pictura nicht allein durch den Umriss der Verse konstituiert, sondern in ihren Einzelheiten erst während des Rezeptionsprozesses im Flottieren zwischen bildlicher und textueller Wahrnehmung des Gebildes sichtbar wird. Als Motto fungiert die Überschrift des Gedichts, die über den Verweis auf das Alte Testament Aspekte des Freundschaftsthemas implizit

37 Albrecht Schöne: Emblematik und Drama im Zeitalter des Barock. München ${ }^{31993, ~ S . ~} 21$. 38 Schöne spricht vom »imperativische[n] Maximencharakter emblematischer Texte« (ebd., S. 45). 
anzitiert - eine Verfahrensweise, wie sie in den Lemmata von Emblemen aus dem 17. Jahrhundert häufig zur Anwendung kommt.

Über die Säulengestalt und dem mit dieser verbundenen Symbolgehalt wird in Karsts Figurengedicht nicht nur die Beständigkeit und hoffnungsfrohe Stärke wahrer Freundschaft ausgewiesen, sondern darüber hinaus dem Freund, quasi als Institution, ein Denkmal gesetzt. Das Baumaterial der Wörter ist so eingesetzt, dass einzelne metaphorische Beschreibungen, aufgrund der für die visuelle Poesie charakteristischen Verschmelzung von Text und Bild, zu eigentlichen stofflichen Säulenkomponenten werden: Die verwendeten Sprachbilder avancieren zu pikturalen resp. materialen Bestandteilen der Ehren-Säule, sobald sich im Lektüreprozess die Vorstellung des reliefgeschmückten Schafts nach dem Vorbild antiker Siegessäulen einstellt. Nicht zuletzt die emblematische Struktur des Gebildes führt dazu, dass dieses Figurengedicht über die spezifische casuallyrische Funktion hinaus das Wesen der Freundschaft im Allgemeinen und auch den aus diesem resultierende Aufforderungscharakter, eine Freundschaft einzugehen, buchstäblich vor Augen stellt.

Mit der Säulenform ist ein gut etablierter Umriss gegeben, der in der frühneuzeitlichen visuellen Poesie weit verbreitet war und satztechnisch betrachtet nicht durch figurale Komplexität hervorsticht. Karsts Gedichtsammlung bietet aber auch Wort-Bild-Konstellationen, die das intermediale Spiel eher unkonventionell und erfindungsreich gestalten und in ihrem graphischen Arrangement geradezu modern anmuten. Um eine solche handelt es sich beim Figurengedicht für Wolffgang Dietherich Badern, das sich ebenfalls in der Sammlung der Neujahrscarmina befindet. Der Adressat ist Doktor beider Rechte und »Hochgräffliche[r] Ysenburgische[r] fürnehme[r] Rath « ${ }^{39}$, die einleitenden Alexandriner sind nicht mit einem expliziten Datum versehen, nennen die Thematik des Jahreswechsels aber bereits zum Auftakt: »Seht! wie das alte Jahr nun gantz und gar verschwunden! $«^{40}$ Die insgesamt 56 Widmungsverse, die der Text-Bild-Konfiguration vorangestellt sind, gehen vor allem auf die Vergänglichkeit des Irdischen ein, die mit dem Neujahrstag besonders ins Bewusstsein rückt, überbringen des Weiteren gute Wünsche an den Dedikanden und kündigen zum Schluss das Figurengedicht als besondere Gabe wie folgt an: »Hiemit gehabt Euch wohl / und lebet stäts mit Freuden | Und nemt zum neuen Jahr diß Hertzgen / so das Leiden | Den Prast / die Last und Pein der Frommen bildet ab / | Dieweil ich eurer Gunst sonst nichts zu schencken hab. ${ }^{41}$

39 Karst (Anm. 22), S. 44.

40 Ebd.

41 Ebd., S. 45. 
Das auf der nachstehenden Seite präsentierte Figurengedicht stellt denn auch, wie unschwer zu erkennen ist, ein Herz dar, das von einem Pfeil durchbohrt wird, wobei außerdem ein leicht geschlängeltes Etwas aus dem Herz nach oben entweicht (Abb. 8). Darüber hinaus besitzt die Text-Bild-Kombination eine Art Zuschrift, die sich auch als Sockel des Figurengedichts interpretieren lässt. Die Herzform als solche ist in der visuellen Poesie des 17. Jahrhunderts gang und gäbe, die geradezu perspektivische Kombination mit dem durchspießenden Pfeil hingegen ähnlich ausgefallen wie andere Figurengedichte Karsts, beispielsweise diejenigen in Bett- oder Wiegengestalt. ${ }^{42}$

Mit der abgebildeten Objektkonstellation liegt als erster Gedanke derjenige an Amor nahe, an weltliche Liebe und Verliebtheit. Tatsächlich ist das Herz aber auch ein Symbol, das gerade in der Emblematik und der Erbauungsliteratur des 17. Jahrhunderts immer wieder als Zeichen der spirituellen Liebe zwischen dem Gläubigen und Jesus Christus gebraucht wurde. $\mathrm{Zu}$ nennen ist hier einerseits die sogenannte Herzemblematik, die sich vor allem in der ersten Hälfte des 17. Jahrhunderts einiger Beliebtheit erfreute. Das Herz als Sitz des religiösen Gefühls und als Metonymie für die menschliche Seele bot ein wunderbar vielseitiges und anpassungsfähiges Motiv, das sich in den Picturae beinahe beliebig in Szene setzen ließ: Ganze Emblembücher zeigen Dutzende von Herzabbildungen in mannigfaltigen Kontextualisierungen. ${ }^{43}$ Andererseits sind emblematische Erbauungsbücher wie beispielsweise die 1624 erstmals gedruckten Pia desideria des flämischen Jesuiten Herman Hugo zu erwähnen, die die Amorette als Bildsujet aus der weltlichen Liebesemblematik übernommen und auf die Beziehung zwischen Mensch und Gott übertragen haben: Die Pictura veranschaulicht in diesen Emblembüchern meist eine Szene mit zwei Figuren, die Amor divinus als Putto mit Nimbus und Anima abbilden, wobei das Verhältnis zwischen Anima, der menschlichen Seele, die weiblich gedacht wird, und der männlich vorgestellten göttlichen Liebe, die Züge von Christus trägt, auf der Vorstellungswelt der Brautmystik basiert. ${ }^{44}$ Herz- und Amorettenmotiv finden sich auch in Verknüpfung

42 Vgl. ebd., S. 121, 143, 206.

43 Ein frühes Beispiel sind die Emblemes, Ou Devises Chrestiennes der Hugenottin Georgette de Montenay, im Jahr 1571 erstmals in Lyon veröffentlicht, in denen das Herzmotiv allerdings nur sporadisch vorkommt. Vollständig dem Herzmotiv gewidmet sind die Emblemata Sacra des lutherischen Theologen Daniel Cramer, die 1624 in zwei Teilen erschienen sind. Siehe weiterführend: Sabine Mödersheim: »Domini Dctrina Coronat «. Die geistliche Emblematik Daniel Cramers (1568-1637). Frankfurt a. M. 1994 (Mikrokosmos; 38).

44 Bei Herman Hugos Pia desideria handelt es sich um eines der erfolgreichsten Emblembücher überhaupt. Das Werk fand sofort starken Anklang, so dass es in den folgenden 200 Jahren allein auf lateinisch über 50 Ausgaben erhielt. Dazu kamen Übersetzungen und Adaptationen in 


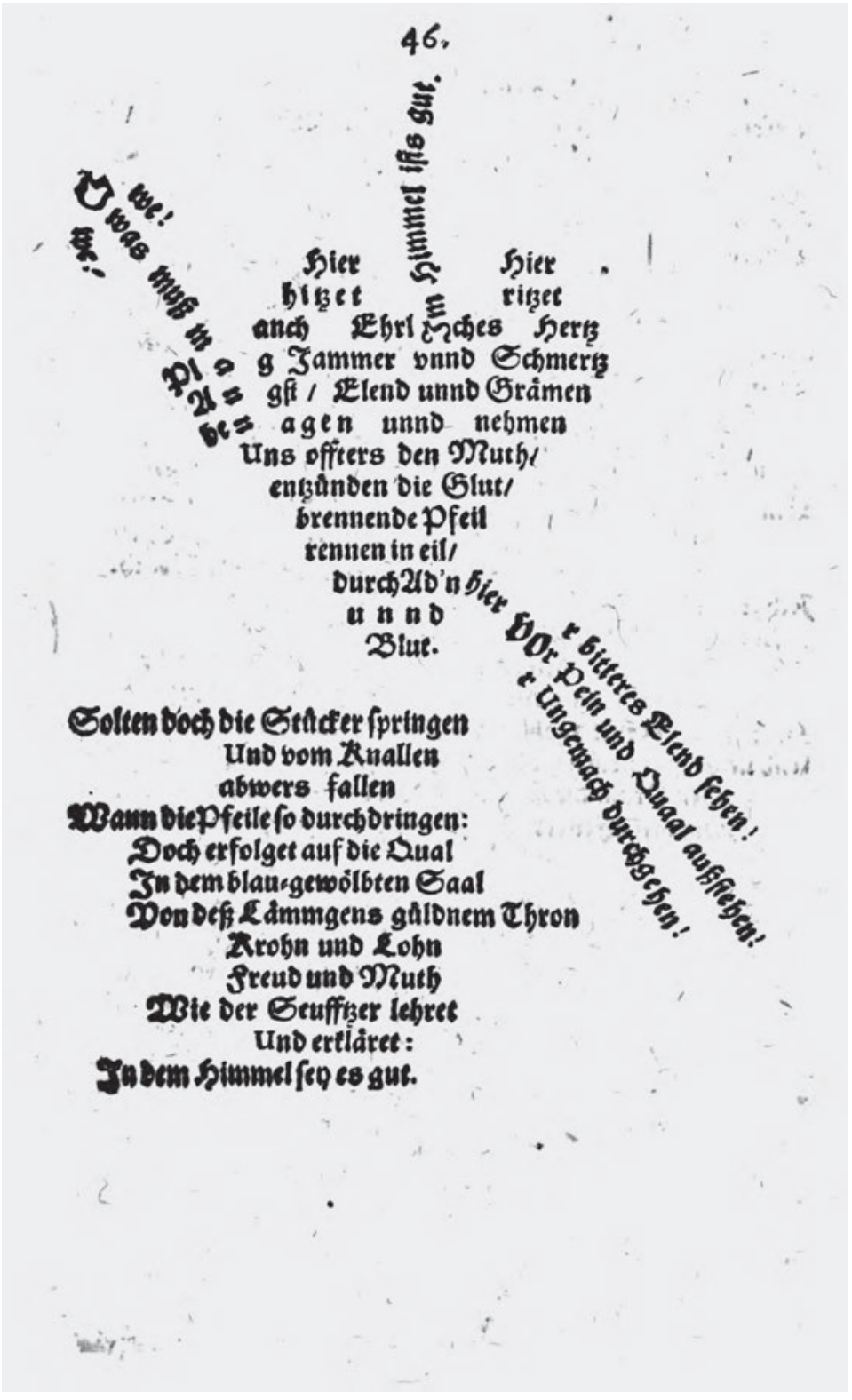

Abb. 8: Johann Rudolf Karst, Deutscher Dicht-Kunst Lust- und Schau-Platz, Frankfurt a. M. 1667, S. 46 [Bayerische Staatsbibliothek: P.o.germ. 707 k]. 
miteinander, etwa im ebenfalls sehr beliebten Emblembuch Schola cordis von Benedict van Haeften. ${ }^{45}$

Es ist davon auszugehen, dass der zeitgenössische Leser von Karsts Herzgedicht die erwähnten Emblemtraditionen kannte, da sie zu den populärsten Intermedialitätsphänomenen seiner Gegenwart gehörten. Eine Deutung der abgebildeten Herzkonstellation im Sinne der aktuellen Frömmigkeitsdiskurse legen zudem die - oben zitierten - Alexandriner nahe, die das Figurengedicht ankündigen. Auf der Basis der genannten Bildtraditionen wird die damalige Rezipientin auch die dochtartige Linie, die aus dem Herz herauswächst, bereits vor der verbalen Lektüre als Flamme interpretiert haben, die für die entzündete Liebe zu Gott steht (vgl. Abb. 5 u. 6).

Wendet sich der Leser nach dem ersten Augenschein der literalen Seite des Figurengedichts $\mathrm{zu}$, sieht er sich einer doppelten Herausforderung gegenüber: Nicht nur ist in diesem Gedicht die traditionelle Leserichtung aufgegeben zugunsten einer komplexen Linienführung, die die Objekte sichtbar macht - so dass der Buchstabentext nur dann vollständig entziffert werden kann, wenn das Buch mehrfach gedreht und hin und her bewegt wird -, sondern es gibt auch keinen Anhaltspunkt, wo überhaupt mit der Lektüre begonnen werden soll. Aufgrund der Verknüpfung mehrerer miteinander verbundener Gegenstände ist bei diesem Gebilde nicht von vornherein klar, welche Versabfolge die sinnreichste ist, so dass erst die Mehrfachlektüre der einzelnen Objektbahnen und die damit verbundene Vertiefung in das Figurengedicht die Bedeutung der Gesamtkonstellation aufschließen kann.

Da für die Entzifferung der Herz-Verse das Blatt zunächst nicht gedreht zu werden braucht, ist ein Einstieg mit diesen Zeilen erleichtert, was durch das doppelte deiktische »Hier«, das den wandernden Blick gleichsam einfängt, zudem nahegelegt wird. Allerdings kann der lineare Leseakt auch bei dieser Figur nicht uneingeschränkt vollzogen werden, da Herz, Pfeil und Flamme derart mitein-

die meisten europäischen Sprachen wie französisch, englisch, holländisch, dänisch, polnisch, russisch, spanisch oder portugiesisch. Auf Deutsch beispielsweise gibt es über ein Dutzend unterschiedliche Übersetzungen und Bearbeitungen, sowohl katholische wie auch protestantische. Siehe weiterführend etwa: Gabriele Dorothea Rödter: Via piae animae. Grundlagenuntersuchung zur emblematischen Verknüpfung von Bild und Wort in den »Pia desideria« (1624) des Herman Hugo S. J. (1588-1629). Frankfurt a. M. 1992 (Mikrokosmos; 32).

45 Die Schola cordis des belgischen Benediktiners Benedict van Haeften ist 1629 in Antwerpen erstmals ediert worden und hat zahlreiche Auflagen und Übersetzungen erfahren. In Haeftens Erbauungsbuch wird jede der 55 lectiones durch einen Kupferstich eingeleitet, der eine Szene mit einem Herz zeigt, um das sich der geflügelte Amor divinus und die weiblich dargestellte Anima in irgendeiner Weise bemühen oder sich an ihm zu schaffen machen. Das Motto nimmt immer auf das Herz Bezug, das im Titel des Werks prominent genannt ist. 
ander verwoben sind, dass einzelne Buchstaben an der Abbildung von jeweils zwei Gegenständen teilhaben, was einerseits zur Folge hat, dass das Gebilde dreidimensionale Plastizität erhält, andererseits aber auch dazu führt, dass die Buchseite (oder der Kopf der Rezipientin) auch schon bei der verbalen Decodierung des Herz-Textes gedreht werden muss.

Die über den pikturalen Wahrnehmungsmodus als Herz identifizierte Figur wird mit dem Beginn der Verslektüre mit »manch ErlIche[m] Hertz« gleichgesetzt, womit offensichtlich - im Sinne der zeitgenössischen Erbauungsliteratur die frommen Christen gemeint sind. Beschrieben wird, passend zu den vorausgegangenen Alexandrinern, die irdische Lebenssituation des Gläubigen, die durch »Plag Jammer unnd Schmertz | Angst / Elend unnd Grämen« geprägt ist. Die Unwegsamkeiten des Diesseits führen aber laut Verstext auch dazu, dass sie die flammende Liebe zu Gott entfachen: sie »entzünden die Glut«. Die seufzenden Verse, die den Pfeil illustrieren, greifen dieses Thema auf und betonen ihrerseits, welch Qual und Elend das Erdenleben ausmacht - wobei die graphische Pointe hier darin besteht, dass die den Pfeilschaft abbildenden Wörter drei Mal den ersten Halbvers konstituieren und also lesend zu wiederholen sind, während sich die jeweils zweiten Vershälften mit differentem Wortlaut in die Befiederung verlaufen. Als Kontrapunkt formuliert hingegen die Flamme: »Im Himmel ists gut." Dabei zeichnet sie das nach oben hin trachtende Streben der göttlich entzündeten menschlichen Seele mittels der Laufrichtung der Buchstaben gerade nach.

Mitder Lektüre des verbalen Texts wird das abgebildete Herz also zum frommen Gläubigen, der auf Erden leidet, aber gleichzeitig in Gottesliebe entflammt ist und sich nach dem Himmel sehnt. Der durch das Herz gestoßene Pfeil erhält dabei eine ambivalente Deutung, die die christliche Dichotomie von Diesseits und Jenseits, von hiesigem Jammertal und dortiger göttlicher Vereinigung aufgreift: So ist der Pfeil einerseits Marterwerkzeug, das die christliche Seele »ritzet«, wie es in den Herz-Versen heißt - womit der Bezug zum Leidensweg Christi hergestellt ist, zu dem sich der Rezipient, lesend und betrachtend, in ein Verhältnis setzt. »Heilands Passion-Zeug « in Figurengedichten abzubilden, um dadurch Frömmigkeit zu beweisen, dies rät Sigmund von Birken in seiner Poetik Deutsche Redebind- und Dicht-Kunst einige Jahre später. ${ }^{46}$ Andererseits ist der Pfeil aber auch Zeichen der flammenden Liebe und der Verbindung des Menschen mit Gott (oder wie es die Herzfigur nennt: »hitzet«). Der das Herz durchdringende Pfeil und die Flamme stehen beide für die Liebesglut, die der Gläubige zu Christus empfindet und die er, während er sich meditativ in das Figurengedicht versenkt, zu spüren vermag. Beide markieren sie schließlich die Beschwerlichkeit des Erdenlebens -

46 Siehe Anm. 21. 
was sich wiederum in der aufwändigen und mühevollen Rezeption der Text-BildKonfiguration spiegelt, die der Leserin immer wieder abverlangt, den 'geraden (Lektüre-)Weg zu verlassen und Hindernisse zu bewältigen.

Die fromme Ernsthaftigkeit, die in diesem Figurengedicht steckt, wird durch die in spielerischer Leichtigkeit formulierten Zusatzverse etwas zurückgenommen, die auf derselben Blattseite abgedruckt sind (und zum festlichen sowie nach vorne gerichteten Akt des Jahreswechsels zurückführen). Diese sprechen, auf den Flammen-Vers der Text-Bild-Konstellation rekurrierend, die hoffnungsfrohe Botschaft des Paradieses aus, die dank Jesu Kreuzestod für die Menschen eröffnet worden ist und die das irdische Dasein unter dem Himmelszelt - »In dem blau-gewölbten Saal« - erträglicher macht.

Alles in allem ist das als Neujahrsdedikation konzipierte Figurengedicht für Wolffgang Dietherich Badern durchdrungen von allgemeinen Gedanken religiöser Erbauung, wie sie in der zeitgenössischen Emblematik omnipräsent sind. Karst bestätigt damit, was er bereits im Vorwort der Sammlung ankündigt, dass nämlich die Carmina zu allererst für den frommen Dienst an Gott formuliert sind. Häusliche Andacht und anlassgebundene Widmung gehen hier Hand in Hand auch dies eine in der Lyrik des 17. Jahrhunderts weit verbreitete Praxis. Bemerkenswert ist an diesem Gedicht der kreative Umgang mit dem Buchstabenmaterial, der in seiner spielerischen Art aus heutiger Sicht gar nicht so richtig zum frommen Thema passen will und an die visuelle Poesie der Moderne erinnert, etwa an die Calligrammes von Guillaume Apollinaire. Doch zeigt das vielseitige intermediale Spiel figuraler Gedichte in der frühen Neuzeit und der verbreitete Einbezug derartiger Elemente in die damalige Erbauungsliteratur, dass sich religiöser Ernst und dichterische Kombinatorik im 17. Jahrhundert nicht ausschließen, im Gegenteil. ${ }^{47}$

47 Siehe dazu auch die grundlegende Untersuchung: Alfred Liede: Dichtung als Spiel. Studien zur Unsinnspoesie an den Grenzen der Sprache. Neu hg. von Walter Pape. Berlin 1992 (Repr. d. Ausg. Berlin 1963). 